\title{
Evolution of Family Medicine in Kenya (1990s to date): a case study
}

\author{
PM Chege ${ }^{a *}$, J Penner ${ }^{b}$, P Godoy-Ruizc, V Kapoor ${ }^{b}$, J Rodas' and K Rouleau \\ ${ }^{a}$ Department of Family Medicine, Moi University College of Health, Eldoret, Kenya \\ ${ }^{b}$ Department of Family Medicine, University of British Columbia, Vancouver, Canada \\ 'Department of Family \& Community Medicine, University of Toronto, Toronto, Canada \\ *Corresponding author, email: pcmasemiano@mu.ac.ke
}

Background: Successful Family Medicine practices and academic programmes are found in western countries, Australia, Singapore, Cuba and among other non-western countries. Documenting the enablers and challenges of different contexts would, it is hoped, inform current and future process of developing academic and practice programmes in Family Medicine in countries where the discipline is starting.

Methods: A qualitative study was undertaken that conducted a focused literature review and in-depth interviews of key informants on the early development of the Family Medicine in Kenya. All interviews were audio recorded. Pattern matching, explanation building, time-series analysis and logic models were used in analysis.

Results: Representatives of Kenyan and foreign organisations worked well as a team to write and implement the first curriculum of Family Medicine. The challenges include lack of teachers; starting a graduate programme in medical schools that did not have one and starting these health services delivery departments in a system that did not have any.

Conclusions: The main enablers of the evolution of Family Medicine in Kenya include committed partnerships and teamwork among Kenyan and non-Kenyan stakeholders. The challenges include the lack of Kenyan teachers of the programme and the introduction of a new discipline.

Keywords: academic programmes, challenges, enablers, Family Medicine evolution, Kenya

\begin{abstract}
Introduction
Since the Alma-Ata conference in 1978, Primary Health Care (PHC) and Primary Care (PC) have been given some focus as the foundation on which health equity and comprehensive care among citizens could be built.., The World Health Organization (WHO) support for primary care was demonstrated by World Health Report of $2008 .^{3}$
\end{abstract}

There is compelling evidence that in countries where PC has been given its due consideration in national health policy, better and cost-effective health outcomes have been documented. ${ }^{4,5}$

Sub-Saharan Africa (SSA), with the region's immense economic challenges, would do much better using its limited resources in improving health by enhancing primary care for the citizens. This, unfortunately, has not been the case and the results are well demonstrated by the health indicators in countries of this region. ${ }^{9,14}$

Most FM departments in other SSA countries are in the budding stages except for South Africa and Nigeria. ${ }^{4}$ Significant progress in the establishment of FM departments in medical schools in this region has occurred in the last decade due to concerted efforts by organisations such as the Primary Care \& Family Medicine Education (Africa) Network (Primafamed); ${ }^{5}$ The WHIG (a group of general practitioners in The Netherlands with a strong commitment to primary care in an international perspective); Maastricht University centre for international cooperation in academic development (MUNDO); Institute of Family Medicine (INFAMED); the Department of Community and Family Medicine, University of Toronto; World Organization of Family Doctors (WONCA) and individual advocates (the Late John D. Ross of the University of Toronto), Prof. Jan De Maeseneer of Primafamed, Dr
Geraldine van Kasteren of MUNDO, Dr Jean W. Kagia and Dr Bruce Dahlman both of INFAMED, among others).

FM training in Kenya was introduced as a formal post-medical school training programme at Moi University in 2005. Other Kenyan medical schools with FM training programmes include: the Aga Khan University Hospital in Nairobi, Maseno University, Kabarak University and Kenyatta University. Aga Khan and Kabarak are both private universities.

This case study summarises the major steps in the evolution of FM in Kenya. It describes enabling factors, and also highlights barriers that may be hindering the progress that was projected.

The study builds on a previous description of the early development of the FM training programme at Moi University by Ronald Pust et al., which provides rich insight into the period spanning the late 1990 s and the early 2000 s. $^{6}$

\section{Background of Kenyan demography and the public health services}

\section{Demographics}

The Kenya National Bureau of Statistics estimated the Kenyan population at 46 to 47 million in 2015 . It should be noted that the last documented national census was in 2009 .

According to the 2014 Global Health Observatory Statistics, the Kenyan gross national income per capita (PPP) was 1290 US dollars compared with 6 800, 2 970, and 1590 for South Africa, Nigeria and Ghana respectively. The Canadian PPP was USD 51 630 during the same year. ${ }^{8}$ 
According to the Kenya Health and Demographic Survey (KHDS 2008-2009) published in 2010, children below five years old represented $16 \%$, those between 5 and 19 years old 39\%, while those between 20 and 59 years old accounted for $39 \%$ of the total population. Persons older than 60 years represented a mere $6 \%$. This age distribution is typical of SSA where children and adolescents form the largest segment while the economically productive age group forms a small proportion of the total. That report also documented high levels of widespread poverty, particularly in rural areas, with only $7 \%$ of women and $10 \%$ of men having more than secondary school education; infant mortality was at 52 deaths per 1000 live births while under-five mortality was 74 per 1 000. It also reported that an estimated $43 \%$ of births occurred in health facilities and maternal mortality was at 488 per 100000 live births. These worrying rates have not changed significantly as can be seen the KHDS of $2014 .{ }^{19}$

\section{Organisation of Kenyan public health services}

The organisation of public health services in Kenya is summarised in Appendix 1. Level one services, which comprise community units (a unit serves a population of 5000 ) under a community health volunteer (CHW) worker who is supervised by community health extension workers (CHEW). The CHEWs have a certificate or diploma training in public health or nursing while the CHWs receive several weeks of preparatory training. ${ }^{10,11}$

The CHWs facilitate individuals, families and communities to carry out appropriate health behaviour. The basic training the CHWs receive provides them with basic health education to recognise symptoms and signs that require referral to the health facilities.

Primary care is offered in dispensaries and health centres (levels 2 and 3), by diploma clinicians and nurses. Hospitals, where doctors (medical, pharmacy and dental) are in post are level four, and may also have one or two primary care specialists who include family physicians, general surgeons, paediatricians and obstetricians. One of these specialist doctors also works as the executive manager of the hospital.

The health indices for Kenya, though reported to have improved in the last decade, reflect the poor state of public health services management (Appendix 2). ${ }^{12}$

\section{Methodology and research activities}

Our case study was developed applying a focused literature review and interviews of key informants (consent form available in Appendix 3). The literature review was focused on key published and unpublished documents related to the organisation of government-run health services in Kenya and also the development and implementation of FM in Kenya.

Published data were accessed using Pub Med, the Kenya Ministry of Health website (http://www.health.go.ke) and Google Scholar. The Moi University College of Health Sciences Learning Resource Center was a useful source of hard copies of relevant articles and documents.

The key informants (KIs) were a convenient sample selected from a list of 18 names of stakeholders involved in the early stages of development of the FM programmes. They included universityemployed and non-university individuals who supported the programmes by lobbying for local and international support. Some of the Kls provided technical assistance, participating in curriculum development, vetting of the first applicants for the programmes and as honorary lecturers.
The interviewed Kls included leaders of international collaborating organisations and institutions, officials of the Kenyan medical practice regulatory authority, Kenyan Ministry of Health officials and graduates of the Moi University FM programme.

All the interviews were conducted by the principal investigator (PI) using semi-structured open-ended questions as guide (Appendix 4). The interviews lasted between 40 and 90 min and were all audio-recorded.

Data were stored in the Pl's personal computer in folders for transcription.

Pattern matching, explanation building, time-series analysis and logic models were used in analysis.

Ethical approval to conduct the study was given by the Moi University College of Health Sciences Institutional Ethics and Research Committee (IREC). Consent of the Kls was sought through personal visits, telephone calls and email messages by the PI. Verbal consent was sought by telephone while signed consent was collected from those visited.

\section{Results}

Ten key informants were interviewed. All available and consenting Kls were interviewed. Four of those who were not interviewed had since retired and contact had been lost, three did not respond to messages inviting them to the interview and one was deceased.

The literature review and key informant interviews provided key findings regarding the evolution of FM in Kenya.

These findings are presented in four broad categories below: the perception of FM in Kenya; process and milestones of FM development; enablers; and challenges,

\section{A. Perception of FM in Kenya}

Van der Voort et $a l .^{13}$ reported challenges that hindered a rapid rise in the number of family doctors in Kenya as poor appreciation of the role of the family doctor within the health delivery system. ${ }^{14}$

According to van der Voort et al. the following points summarise how the different groups perceived the family doctor in the Kenyan health delivery system:

(i) General population: the literacy level in Kenya being low, as reported earlier, for the majority of rural Kenyans, persons working on hospitals are 'physicians'. So family doctors working in these facilities, in which they run outpatient clinics, conduct teaching ward rounds as 'attending physicians' and perform significant major emergency general and reproductive health surgery place them in positions of consultants.

(ii) The policy-makers in areas where the family doctors have been posted have reported these graduate trained generalists as 'the wonder doctors' who demonstrate unique all-round competencies.

(iii) Medical school faculty members from different specialist backgrounds in most cases have tended to look down on the family doctor and view them as intruders to the specialties.

(iv) The other members of academia (schools that teach non-healthrelated courses in the universities) have difficulty telling the difference between the disciplines. 
Table 1: Key milestones in the development of FM in Kenya (as narrated by the key informants)

\begin{tabular}{|c|c|}
\hline Period & Events \\
\hline \multirow{7}{*}{ 1998-2001 } & $\begin{array}{l}\text { - First discussion on the need for a Kenyan-trained } \\
\text { high-quality generalist occurred during a Christian } \\
\text { Health Association of Kenya (CHAK) stakeholders } \\
\text { meeting in Nairobi }\end{array}$ \\
\hline & - College of Family Medicine (COFAMED) formed \\
\hline & $\begin{array}{l}\text { - Members of COFAMED lobbying for support to } \\
\text { develop FM curriculum that would serve Kenyan } \\
\text { primary care needs }\end{array}$ \\
\hline & $\begin{array}{l}\text { Moi University accepts to host the FM programme } \\
\text { COFAMED; changes name to INFAMED }\end{array}$ \\
\hline & - Stakeholders meeting on curriculum development \\
\hline & $\begin{array}{l}\text { Stakeholders included representatives INFAMED, CHAK, } \\
\text { Ministry of Health, Kenya Medical }\end{array}$ \\
\hline & $\begin{array}{l}\text { Practitioners and Dentists Board (MP\&DB), Moi University } \\
\text { and Maastricht University }\end{array}$ \\
\hline \multirow{6}{*}{$2002-2004$} & $\begin{array}{l}\text { - INFAMED and Moi University identify three mission } \\
\text { hospitals and one sub-district suitable for clinical } \\
\text { teaching rotations }\end{array}$ \\
\hline & $\begin{array}{l}\text { - Approval of MMed FM curriculum by Moi University } \\
\text { Senate, MP\&DB and Kenya Commission for University } \\
\text { Education }\end{array}$ \\
\hline & $\begin{array}{l}\text { - Recognition of FM as a medical specialty by the } \\
\text { MP\&DB }\end{array}$ \\
\hline & $\begin{array}{l}\text { - Registration of Kenya Association of Family } \\
\text { Physicians (KAFP) }\end{array}$ \\
\hline & $\begin{array}{l}\text { Prof. Ronald Pust of the Department of Family } \\
\text { Medicine University of Arizona, USA and Prof. Peter } \\
\text { Manscot of the University of Utrecht appointed as } \\
\text { visiting professors and co-heads of the Division of } \\
\text { Family Medicine }\end{array}$ \\
\hline & $\begin{array}{l}\text { - First } 10 \text { applicants for MMed FM interviewed in } \\
\text { Eldoret }\end{array}$ \\
\hline \multirow{7}{*}{2005 to present } & $\begin{array}{l}\text { - First three students admitted in January } 2005 \text { and } \\
\text { five more in September } 2005\end{array}$ \\
\hline & - Writing of the proposed Family Medicine policy ${ }^{15}$ \\
\hline & - First three graduates in December 2008 \\
\hline & $\begin{array}{l}\text { - The Aga Khan University Hospital develops MMed FM } \\
\text { curriculum and admits first students in } 2012\end{array}$ \\
\hline & $\begin{array}{l}\text { School of Medicine Maseno University develops } \\
\text { MMed FM curriculum and admits first four students } \\
\text { in September } 2014\end{array}$ \\
\hline & $\begin{array}{l}\text { Kenyatta and Kabarak Universities develop MMed } \\
\text { curricula and admit first cohorts in September } 2015\end{array}$ \\
\hline & $\begin{array}{l}\text { By December 2015, Moi University FM programme } \\
\text { had graduated } 29 \text { family doctors, all serving within } \\
\text { Kenya }\end{array}$ \\
\hline
\end{tabular}

\section{B. Development process and milestones}

Milestones in the development of FM in Kenya as presented by the Kls and also from the literature review are presented in Table 1.

The nuances of some of these milestones are best expressed through quotations from some of the key informants:

In 1998, during a CHAK stakeholders' meeting in Nairobi, the members observed that the expatriate family doctors in the CHAK hospitals were playing a very crucial role in the delivery of outpatient and inpatient care that included medical and emergency surgical services that was estimated at about $40 \%$ of all health services in rural Kenya. It was agreed that these mainly expatriate graduate trained generalist doctors should find ways of training Kenyan doctors to work as colleagues at that level. The stakeholders were mainly from CHAK and MAP international. (Key Informant [KI] 5: Specialist in reproductive health who is a leader in the $\mathrm{CHAK}$ )

We formed and registered the College of Family Medicine (COFAMED), which was to coordinate the training of Family Medicine in Kenya and neighbouring countries. A competency-based curriculum that borrowed some aspects of rural United States primary care residency practice but guided by the Kenya health needs was drafted. The drafters were guided by MEDUNSA, CANMEDS and the STFM curricula. Initially we planned to implement this curriculum as a MEDUNSA programme with clinical rotations in Kenyan hospitals. (KI 5)

In 1999, as the academic director of the Kenya Medical Practitioners and Dentist Board, I met with representatives from $\mathrm{CHAK}$ who had been referred to the board by the Kenya Commission for Higher Education (CHE). The name of the commission has since change to 'Commission for University Education (CUE)'.

The board concurred with $\mathrm{CHE}$ that it was not allowable to offer a MEDUNSA degree in Kenya without the MEDUNSA having a Kenyan campus.

COFAMED was advised to work with the Kenya medical schools to offer the programme.

As dean of the Moi University Faculty of Health Sciences, I offered to present the request to the Moi University Senate on condition that the COFAMED changed name from college to institute to minimise logistic challenges that would arise if a college was working under a university school.

COFAMED agreed to change name to the Institute of Family Medicine (INFAMED).

The MMed FM curriculum was prepared for the Moi University programme and approved by the MU Senate.

Moi University offered to start the master of medicine (MMed) Family Medicine programme as plans were also advanced to starting MMed Medicine and MMed Paediatrics. The first students in the three disciplines were admitted in January 2005. (KI 6: Kenyan cardio-thoracic surgeon, who was then dean of the Moi University faculty of Health Sciences and played a very crucial role in the starting of FM training in Moi University)

I got involved in the early stages of the Moi University FM curriculum development as a visiting lecturer in the Moi University department of behavioural sciences in 2001 when the then dean spoke with me about it. It was exciting news to me and my colleagues back home and we enlisted as stakeholders in the development of the programme. We offered our input on development of a Kenyan postmedical school generalist curriculum that would address the Kenyan health services needs. We have offered support for the programme as visiting teachers and funding advocacy for FM in Kenya mainly through a group of GPs 
in my country's association of GPs that are registered as 'Friends of Moi University' and also through MUNDO. (KI 1: Non-Kenyan family doctor working on the faculty at Maastricht University who has been involved in global health initiatives in Africa since the early 2000s)

My first involvement in the development of the Kenyan FM was in 2005 when representatives from Moi University joined other East African delegates in a VLIR-funded workshop on Family Medicine development in SSA that was held in South Africa.

I am the head of the PRIMAFAMED African network and coordinator of its activities since its inception.

The network supports the budding departments of FM in SSA and also coordinates their networking and partnership.

Though we would love to see the successful European model in Africa, we are awake to the fact that primary care and Family Medicine are context specific. (KI 4: Prominent European global advocate for primary health care and Family Medicine for several decades)

Table 2: Enabling factors in the development of FM in Kenya

\begin{tabular}{ll}
\hline Item & Rating \\
\hline Partnership and good working relationship among stakeholders & Very high \\
\hline Graduates of the FM programme assured of a career path & Very high \\
\hline $\begin{array}{l}\text { Recognition as a specialty by the Kenyan Medical practice } \\
\text { regulatory body }\end{array}$ & High \\
\hline $\begin{array}{l}\text { PRIMAFAMED African network guiding development of budding } \\
\text { FM departments through collaboration among themselves and } \\
\text { providing and funding conferences and workshops. Also helped } \\
\text { develop training complexes' infrastructure }\end{array}$ & High \\
$\begin{array}{l}\text { Availability of scholarships and stipend support for Kenyan } \\
\text { government and INFAMED-sponsored students while tuition } \\
\text { support was offered for government-employed students by the } \\
\text { Peter Manscot Fund (of Netherlands) }\end{array}$ & High \\
\hline $\begin{array}{l}\text { Starting of other FM programmes in both public and private } \\
\text { universities. The Moi University curriculum has been used as the } \\
\text { guide by all these departments }\end{array}$ & High \\
\hline \begin{tabular}{l} 
Family Medicine national policy \\
\hline
\end{tabular} & Medium \\
\hline
\end{tabular}

Table 3: Challenges and barriers in the development of Family Medicine in Kenya

\begin{tabular}{ll}
\hline Item & Rating \\
\hline Lack of indigenous Kenyan teachers of FM & Very high \\
\hline $\begin{array}{l}\text { No existing FM departments in the Kenyan health sector. Thus } \\
\text { departments were expected to create their 'homes'. Without the }\end{array}$ & Very high \\
requisite numbers this has remained a challenge & \\
The few teachers, students and graduates remain largely invisi- & Very high \\
ble and the discipline hardly visible & \\
$\begin{array}{l}\text { Poverty as reflected by low purchasing power parity and gross } \\
\text { national income is a factor in the poorly equipped public health } \\
\text { facilities. Family Medicine clinical training for public universities }\end{array}$ & Very high \\
goes on in these facilities. Most applicants for post-medical \\
school training prefer programmes offered in the urban medical \\
schools
\end{tabular}

\section{Enabling factors in the development of Family Medicine in Kenya}

These factors were identified through the key informants and focused literature review

Tables 2 and 3 give brief highlights of the narratives of the key informants.

\section{Discussion}

The emergence of FM training in Kenya was marked by huge goodwill in both Kenyan and non-Kenyan partners. This must be credited to an extensive consultative and all-inclusive process that resulted in teamwork which yielded remarkable success. To sustain that momentum remains daunting because it is apparent that individuals and not institutions may have been the movers of the original team. The exit of some of these individuals from leadership positions in the institutions they represented and their replacement by less enthusiastic occupants in these offices may explain the withering support for Family Medicine in Kenya in the last few years.

The qualitative methods applied were the most suitable to acquire the narrative from those persons directly involved in the conception and nurturing of the early growth of FM in Kenya. The study population was not a large population and most of the responses to the interview questions were similar. This resulted in fairly rapid saturation of the required data.

It is noted that the development of FM in the developed countries where it has taken root was not smooth sailing either. ${ }^{15,16}$

Cynthia Haq summarised the different stages of FM across the globe in the 1970s and 1990s. Most of the barriers documented then are not very different from what we have documented in the Kenyan case. ${ }^{17}$

Michael Kidd in the WONCA guidebook gives a picture of the evolution of FM in Africa and the role of FM in improving health services. ${ }^{4}$ Only time will tell whether what worked well in the developed economies will also work in Africa.

Ssenyonga gives a Ugandan history of FM development that demonstrates how the starting of a new FM programme by wellmeaning foreign individuals without support from government and the medical practice regulatory body could result in major problems when those well-meaning individuals left the African countries. ${ }^{18}$

\section{Conclusion}

The emergence of Family Medicine in Kenya was a demonstration of how coordinated teamwork could make a difficult task appear easy.

Though the different stakeholders were driven by different anticipated benefits of a successful programme, the product was delivered within a reasonable time frame of about seven years from the time the idea was floated.

Acknowledgement - This study was fully funded by the IDRC, Canada and the DFCM, University of Toronto.

Author contributions - PC developed the proposal, collected and analysed data and wrote the manuscript.

JP was involved in the proposal and manuscript writing. 
VK reviewed the proposal and the manuscript.

PR was involved in the proposal and manuscript writing.

KR was the overall coordinator of the case studies and was involved in the proposal and manuscript writing.

\section{Competing interests - None.}

\section{References}

1. International Conference on Primary Health Care. Declaration of Alma-Ata. Alma Ata. 1978. WHO Chron. 1978 Nov;32(11):428-30.

2. World Health Assembly. Resolution WHA62.12: Primary Health care, including health system strengthening. Geneva; WHO Secretariat; 2009.

3. Starfield B, Shi L. Policy relevant determinants of health: an international perspective. Health Policy. 2002;60(3):201-18. http://dx.doi.org/10.1016/S0168-8510(01)00208-1

4. Kidd M. The contribution of family medicine to improving health systems: a guidebook from the world organization of family doctors. CRC Press, Taylor \& Francis Group; 2013, Jun 1. ISBN: 9781846195549

5. De Maeseneer J. Primary health care in Africa: Now more than ever! Afr J Prm Health Care Fam Med. 1(1):132-4.

6. Pust R, Dahlman B, Khwa-Otsyula B, et al. Partnerships creating postgraduate family medicine in Kenya. Fam Med. 2006;38(9):661-6. PubMed: Abstract | Publisher Full Text.

7. Kenya National Bureau of Statistics. Facts and Figures. 2015. Available from: http://www.knbs.or.ke (as pdf doc on-line).

8. World Development Indicators database. World Bank. 2011, July 1 [cited 2016 July 22]. Available from: http://databank.worldbank.org/ data/download/GDP.pdf.

9. Kenya National Bureau of Statistics (KNBS) and ICF Macro. Kenya Demographic and Health Survey 2008-09. Calverton; 2010. PubMed Abstract | Publisher Full Text
10. Taking the Kenya Essential Package for Health to the Community. A strategy for the delivery of LEVEL ONE SERVICES. Kenya: Ministry of Health; 2006 Jun. [PDF: available online]

11. A Manual for Training Community Health Workers. Ministry of Health. Kenya. 2007 Mar. [PDF: available online].

12. Kenya Selected Health indicators. 2012. Available from: http://www. who.int/healthinfo/EN_WHS 2012_Part3.pdf.

13. van der Voort CTM, van Kasteren G, Chege P, et al. What challenges hamper Kenyan family physicians in pursuing their family medicine mandate? A qualitative study among family physicians and their colleagues. BMC Fam Pract. 2012;13(1):370. http://dx.doi. org/10.1186/1471-2296-13-32

14. Ministry of Health: Proposed Family Medicine Policy. Nairobi; 2007. Available on-line as PDF doc.

15. Canadian Family Medicine Heritage. Available from: http:// familymedicineheritage.ca/college-history/.

16. Gigby A (1999). Evolution of British general practice 1850-1948. Hardcover Textbook. Published: 26 August 1999

17. Haq C, Ventres W, Hunt V, et al. Where there is no family doctor. Acad Med. 1995 May;70(5):370-80. http://dx.doi.org/10.1097/00001888199505000-00012

18. Ssenyonga R, Seremba E, Family medicine's role in health care system's in Sub-Saharan Africa: Uganda as an example. Fam Med. 2007;39(9):623-6.

19. Kenya Demographic and Health Survey (KDHS). 2014. Available from: www.knbs.or.ke/index.php?...kenya-demographic-and-healthsurvey...kdhs. 


\section{Appendix 1:}

\section{Organisation of health services delivery [Kenya Health Policy 2012-2030]}

COORDINATION
ORGANISATION

NATIONAL REFERRAL SERVICES: Comprise all secondary and tertiary referral facilities,

which provide highly specialised services. These include:

- General specialisation

- Discipline specialisation

- Geographical/Regional specialisation: highly specialised health care and training and research services for issues of national importance

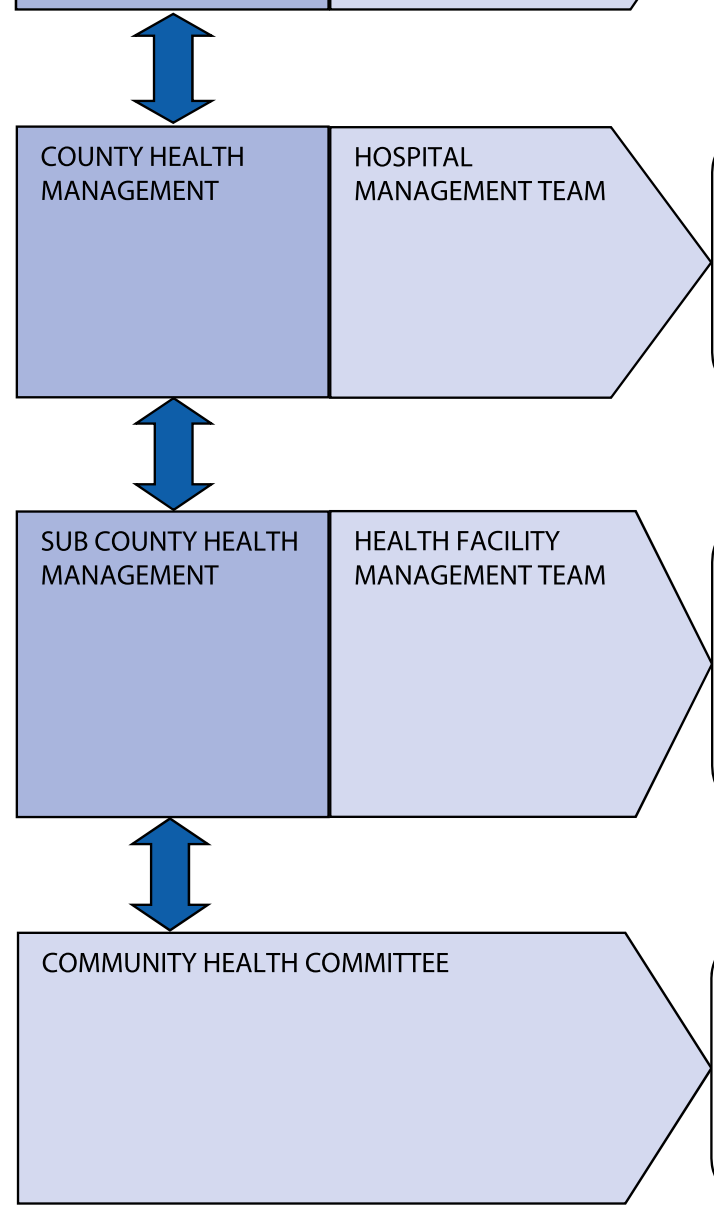

COUNTY HEALTH REFERRAL SERVICES: Comprise all level 4 (primary) hospitals and services in the county, including those managed for non-state actors. Are those constitutionally defined, including:

- Comprehensive in patient diagnostic, medical, surgical and rehabilitative care, including reproductive health services

- Specialised outpatient services

- Facilitate, and manage referrals from lower levels and other referrals

PRIMARY CARE REFERRAL SERVICES: Comprise all level 2 (dispensary) and 3 (health centre) facilities, including those managed by non-state actors. Are those constitutionally defined, including:

- Disease prevention and health-promotion services

- Basic outpatient diagnostic, medical surgical and rehabilitative services

- Inpatient services for emergency clients awaiting referral, clients for observation and normal delivery services

- Facilitate referral of clients from communities and to referral facilities

\section{Appendix 2:}

COMMUNITY HEALTH REFERRAL SERVICES: Comprise community units in the county. Are those constitutionally defined, including:

- Facilitate individuals, households and communities carrying out appropriate healthy behaviours,

- Provide agreed health services

- Recognise signs and symptoms of conditions requiring referral

- Facilitate community diagnosis, management and referral

\section{Kenya Selected Health indices (WHO 2012)}

\begin{tabular}{lcc}
\hline Factor & Global & Kenya \\
\hline Total fertility (per woman) & 2.5 \\
Under-five mortality rate (per 1 000 live births) & 4.5 \\
Maternal mortality ratio (per 100 000 live births) & 73 \\
Prevalence of HIV (per 100 000 population) & 210 & 400 \\
Prevalence of tuberculosis (per 100 000 population) & 511 & 3812 \\
\hline
\end{tabular}




\section{Appendix 3:}

\section{Informed consent form \\ Title: Strengthening primary care through Family Medicine around the world: A Kenyan Case Study}

Principal Investigator: Dr Patrick M. Chege, Head, Department of Family Medicine, Moi University College of Health Sciences.

You are invited to participate in a study being led by the Department of Family Medicine, Moi University College of Health Sciences.

Please note that:

a. Your participation is entirely voluntary.

b. You may withdraw at any time from the study without prejudice.

After you have read the following explanation, please feel free to ask any questions that will allow you to understand the nature of the study.

\section{What this study is about:}

This study is part of a larger research project 'Strengthening primary care through Family Medicine around the world: collaborating towards promising practices' that involves six countries: Kenya, Ethiopia, Indonesia, Mali, Brazil and Canada. In each of these contexts, researchers will conduct a case study on the development of Family Medicine.

Therefore the objective of this study is to produce a Kenyan case study on the development of Family Medicine analysing the key steps, challenges, and enabling strategies in development of Family Medicine in the different universities. This research will be guided by the following research questions:

- How did Family Medicine emerge and develop in the university you were involved in?

- What have been enabling factors and barriers to the strengthening of Family Medicine in your university and Kenya?

- What are the opportunities for strengthening Family Medicine in your university and Kenya?

\section{Why you have been invited to participate:}

You are being invited to participate in the key informant interviews for the project because you are viewed as having a particularly important perspective on Family Medicine in the department in which you were involved and nationally.

Your participation is entirely voluntary. You may refuse to participate altogether, or you may withdraw at any time without any consequences. You will not receive compensation for your participation in this study.

\section{How this study is done:}

The interview will take approximately 30 minutes to one hour. The interview will be in person or by telephone (if in person is not possible). It will involve a series of semi-structured interview questions posed by a member of our research team. The interview will be audio-recorded with your permission and some notes will be made. You may decline to answer any question at any time.

\section{Confidentiality:}

The transcripts from this interview will be anonymised so that you cannot be identified. Only the members of the research team will have access to the transcripts; your responses will be aggregated with those of other participants and summarised in a report.

Your confidentiality will be respected. No information that discloses your identity will be released or published without your specific consent to the disclosure.

All written records, audio recordings, artefacts and questionnaires will be locked in a filing cabinet for two years post-study. Only the investigators and research assistants on this project will have access to the data.

\section{Withdrawal from the study:}

You will have six months from the time of your interview to withdraw from the study. If you communicate your intention to withdraw from the study to the research coordinator or principle investigator, your transcript will be removed from the data-set and excluded from the analysis.

\section{Possible risks and benefits:}

There are no potential physical, social or legal risks for study participants; however, there may be minimal psychological risks. If some professional experiences were unpleasant, then there may be minimal risk associated with their recall. 
Potential benefits of this research include having the opportunity to provide your feedback and asking questions of investigators. The results of this research may also help to inform policy, research or training of family physicians in the future.

\section{Contact for information about the study:}

If you have any questions or desire further information with respect to this study, you may contact the PI on the project Dr Patrick M. Chege, mobile phone: +254-728-024-110 or chege200851@yahoo.com or pcmasemiano@mu.ac.ke

\section{Contact for concerns about the rights of research subjects:}

If you have any concerns about your treatment or rights as a research subject, you may contact the Office of Research Ethics at Moi University College of Health Sciences (http://www.irec.or.ke)

Signing this consent form in no way limits your legal rights against the sponsor, investigators, or anyone else. I have been given the opportunity to discuss pertinent aspects of the research study, to ask questions, and hereby consent to participate in the project outlined. I acknowledge receipt of this consent form.

Participant's name:

Signature: Date:

\section{Appendix 4:}

Semi-structured interview guide

Section 1 - Background questions:

What is your current role/position?

How many years have you been in your current position?

When was the first time you/your institution became involved in the development of Family Medicine in Kenya?

Explain how you were involved then and later and whether you are still actively involved

\section{Section 2 - Perceptions of current state of Family Medicine:}

How do you see the current state of Family Medicine in Kenya?

What changes have you noticed since you started practising? (If an FP in Kenya)

What are the strengths of Family Medicine in Kenya?

What are the challenges?

\section{Section 3 - How did we get here?}

In your opinion what have been some of the key milestone moments for the discipline of Family Medicine?

Can you elaborate?

What do you think have been key ingredients for those significant gains and milestones for the profession?

What have been some of the key challenges for the discipline in the past?

\section{Section 4 - Opportunities}

Knowing our past and our current state, what are the opportunities for Family Medicine in Kenya?

What would strong Family Medicine look like 10-15 years from now? And what would help us get there?

\section{Section 5 - Wrap-up}

Do you have any additional reflections on the past, present or future of Family Medicine in Kenya? 